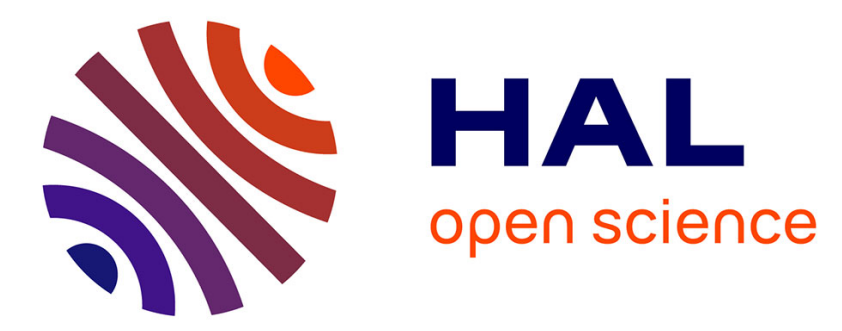

\title{
DNA microarray inspection by interference microscopy
}

Laurent Vabre, Arnaud Dubois, Marie-Claude Pottier, Jean-Louis Stehle, Claude Boccara

\section{To cite this version:}

Laurent Vabre, Arnaud Dubois, Marie-Claude Pottier, Jean-Louis Stehle, Claude Boccara. DNA microarray inspection by interference microscopy. Review of Scientific Instruments, 2001, 72, pp.2834. $10.1063 / 1.1369625$. hal-00627975

\section{HAL Id: hal-00627975 \\ https://hal.science/hal-00627975}

Submitted on 27 Jan 2012

HAL is a multi-disciplinary open access archive for the deposit and dissemination of scientific research documents, whether they are published or not. The documents may come from teaching and research institutions in France or abroad, or from public or private research centers.
L'archive ouverte pluridisciplinaire HAL, est destinée au dépôt et à la diffusion de documents scientifiques de niveau recherche, publiés ou non, émanant des établissements d'enseignement et de recherche français ou étrangers, des laboratoires publics ou privés. 


\title{
DNA microarray inspection by interference microscopy
}

\author{
L. Vabre ${ }^{\text {a) }}$ and A. Dubois \\ Laboratoire d'Optique Physique, CNRS UPR A0005, Ecole Supérieure de Physique et de Chimie \\ Industrielles, 10 rue Vauquelin, 75005 Paris, France \\ M. C. Potier \\ Laboratoire de Neurobiologie, CNRS UMR 7637, Ecole Supérieure de Physique et de Chimie Industrielles, \\ 10 rue Vauquelin, 75005 Paris, France \\ J. L. Stehlé \\ SOPRA-SA, 26 rue Pierre Joigneaux, F 92270 Bois-Colombes, France
}

A. C. Boccara

Laboratoire d'Optique Physique, CNRS UPR A0005, Ecole Supérieure de Physique et de Chimie Industrielles, 10 rue Vauquelin, 75005 Paris, France

(Received 27 November 2000; accepted for publication 4 March 2001)

\begin{abstract}
DNA microarrays are important new objects for biologists, offering new methods for high speed genetic studies. Many of them are manufactured by depositing small spots, containing DNA molecules, on a coated glass slide. The quality of the spots (homogeneity, shape) is an important factor in the quality of the analysis. We have built a Linnik-type interference microscope providing three-dimensional (3D) topographic images of surfaces with a sensitivity of a few tens of picometers in height. This microscope has been applied to obtain 3D images of DNA microarray spots. We demonstrate the ability of the system to reveal the quality of DNA spots. (C) 2001 American Institute of Physics. [DOI: 10.1063/1.1369625]
\end{abstract}

DNA (deoxyribonucleic acid) molecules are the fundamental molecules of life, coding all the genetic characteristics of a particular organism. The DNA molecule has a very long chain structure. The elements of this structure must be known to understand genetic diseases. Since a few years ago, DNA microarrays have appeared as a new tool for fast genome sequencing and transcription analysis. ${ }^{1}$ DNA microarrays are matrices of spots (diameter $<200 \mu \mathrm{m}$ ), each containing many copies of the same DNA molecule [oligonucleotide or polymerase chain reaction (PCR) fragments]. There are various methods of fabrication. The DNA microarrays studied in this note were prepared using the protocol described by Brown. ${ }^{2}$ DNA targets are synthesized using PCR (an "amplification" method, to make many copies of a given piece of DNA molecule) purified and resuspended in $3 \times \mathrm{SSC}$ (saline solution). To enable DNA fixation, the glass slides are coated with polylysine. After spotting, the slides are treated with succinic anhydride in order to block the amino group of the polylysine that has not reacted with the DNA molecules. Microarrays are hybridized with fluorescent cDNA or PCR probes prepared from rat brain mRNA or PCR fragments. Finally, the slides are washed before the reading phase. The hybridization efficiency on all the spots of the DNA microarray is obtained by fluorescence measurements using a confocal microscope. Figure 3(a) shows an example of a good quality fluorescence image that allows a clear image analysis. However, fluorescence images are not always so clean, as can be seen in Fig. 4(a). The image is dominated by the presence of fluorescent "comet tails"

${ }^{\text {a)} E l e c t r o n i c ~ m a i l: ~ v a b r e @ o p t i q u e . e s p c i . f r ~}$ along one direction of the spot matrix. The analysis of an image of this kind is not possible. The reason for this phenomenon is not yet clearly understood. It is likely to be due either to physical parameters of the slide before spotting or hybridization, or to the postspotting experimental protocol. Different slides (homemade or commercial ones) prepared following the same experimental protocol were tested. No correlation was found with the appearance of comet tails. We therefore attribute the origin of the defect to the DNA microarray itself before the hybridization step. In particular, we observed that 2-3 week old slides are of better quality. It would therefore be useful to have a physical criterion in order to determine which slide is suitable for an experiment. Indeed the preparation of DNA solutions and probes is a long, expensive process. A fast, nondestructive characterization process may save a large amount of time and money.

Phase-measurement interferometry (PMI) techniques have been widely used to measure surface topographies. ${ }^{3,4}$ They are noncontact, nondestructive high sensitivity methods. Their height resolution attains $\lambda / 1000$. However, the ability of PMI to image DNA microarray topography and detect flaws that could explain the presence of comet tails in the fluorescence images has not yet been demonstrated.

We have built an interference microscope to realize fullfield topographic images by multiplexed lock-in detection of the optical phase. Our microscope (see Fig. 1) is based on a Michelson interferometer with microscope objectives in both arms (Linnik configuration). The light source is a light emitting diode (LED) at $\lambda=840 \mathrm{~nm}$. The use of a LED is of great interest to us since our system requires the light to be modulated at several kilohertz, as explained later. Moreover, the 


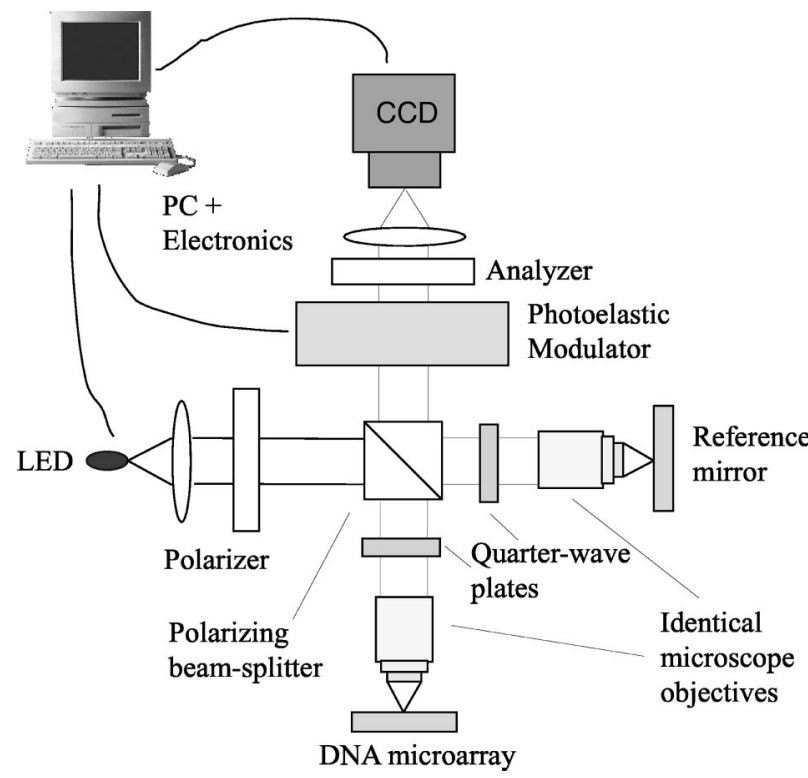

FIG. 1. Schematic representation of our Linnik-type interference microscope. The reference mirror is silicon wafer.

short coherence length and the spatial incoherence avoids parasitic interference signals due to reflections on the optics as well as speckle. We form the image of the reference mirror and of the object on a charge coupled device (CCD) camera array $(256 \times 256$ pixels, $200 \mathrm{~Hz})$. Orthogonally polarized beams are injected in the two arms of the interferometer. Quarter-wave plates are inserted to rotate by $\pi / 2$ the two polarized beams so that the light goes out towards the CCD camera.

The measurement of the optical phase is realized by a lock-in detection performed simultaneously on all pixels of the CCD camera array. A homemade photoelastic modulator (PEM) introduces a periodical phase shift between the two orthogonal polarizations. The interference signal on each pixel can be written as

$$
I(t)=\bar{I}+A \cos (\phi+\psi \sin \omega t),
$$

where $\bar{I}$ is the average or bias intensity, $A$ is the amplitude of the interference signal, $\phi$ its phase, and $\psi$ the amplitude of the PEM modulation at frequency $f=\omega / 2 \pi=50 \mathrm{kHz}$. This signal can be developed with Bessel functions. ${ }^{5}$ We use stroboscopic illumination at $50 \mathrm{kHz}$ to "freeze" the oscillation of the interference fringes. This stroboscopic illumination is periodically shifted by one quarter of the modulation period to obtain four images $S_{0-4}$ with four different fringe patterns. Linear combinations of these four images yield ${ }^{5}$

$$
\begin{aligned}
& S_{0}-S_{1}-S_{2}+S_{3} \propto A \sin \phi, \\
& S_{0}-S_{1}+S_{2}-S_{3} \propto A \cos \phi .
\end{aligned}
$$

A phase map can be calculated from the ratio of these two linear combinations. The height values are then obtained by converting the phase $\phi$ for each pixel into height $h$ according to the formula

$$
h=\phi \cdot \frac{\lambda}{4 \pi} \cdot \beta_{\mathrm{NA}},
$$

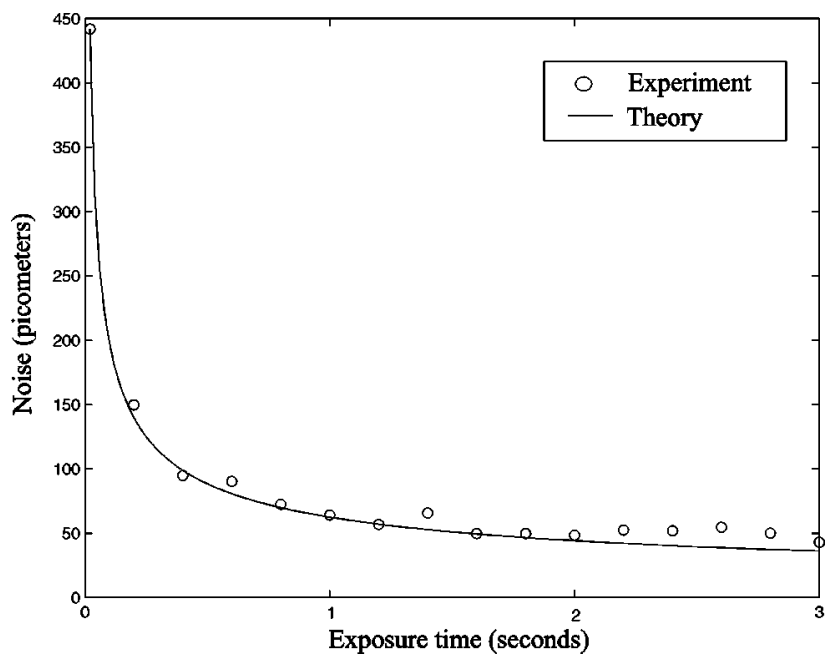

FIG. 2. Phase sensitivity, converted into height values, plotted as a function of integration time. The theoretical curve is obtained assuming that our experiment is shot-noise limited.

where $\beta_{\mathrm{NA}}$ is a numerical aperture (NA) factor, due to the fact that the fringe spacing deviates from $\lambda / 2$ when NA increases. ${ }^{6,7}$

The above algorithm yields to a phase map whose principal values range from $-\pi$ to $+\pi$. The $2 \pi$ phase jumps must then be removed by a process known as phase unwrapping to recover the actual surface shape. However, phase discontinuities larger than multiples of $2 \pi$ between adjacent pixels cause ambiguities for the phase unwrapping process. These discontinuities may result from the surface profile itself if abrupt steps larger than $\lambda / 2$ exist, or from the presence of perturbating elements such as dust particles. To unwrap the phase, we use the so-called Goldstein algorithm, ${ }^{8}$ based on a branch-cut approach, which does not propagate phase errors across the image. All the calculations are performed with a fast Pentium III computer using a Visual $\mathrm{C}++$ compiled interface to control the acquisitions and the calculations. The phase map calculation can be made at a maximum rate of $50 \mathrm{~Hz}$.

Typical spot dimensions of our DNA microarrays are $150-200 \mu \mathrm{m}$ in diameter and less than $10 \mathrm{~nm}$ in height. The height sensitivity of our microscope must be sufficient to detect such small height differences. We measured the noise in phase images by calculating the standard deviation of the difference between two images acquired in sequence. For this measurement, the observed object is a flat mirror. The comparison of the observed and the theoretical dependence of noise (converted into height) on the exposure time is shown in Fig. 2. The theoretical model uses Eqs. (2) to calculate a noisy phase map from four simulated images containing a few fringes (with a contrast of 0.8 ) with additive noise. Assuming the system to be purely shot-noise limited, the standard deviation of this noise is determined by the full well charge storage capability of each pixel of the CCD array (adjusted to $\sim 10^{5}$ ). The experimental results are close to the theoretical predictions, varying as the square root of exposure time. We can reasonably consider that exposure times of 1 or $2 \mathrm{~s}$ are suitable. The noise level is then 


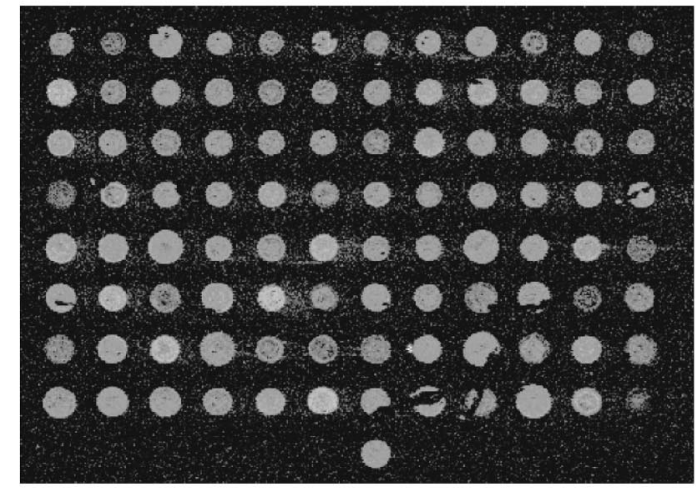

(a)

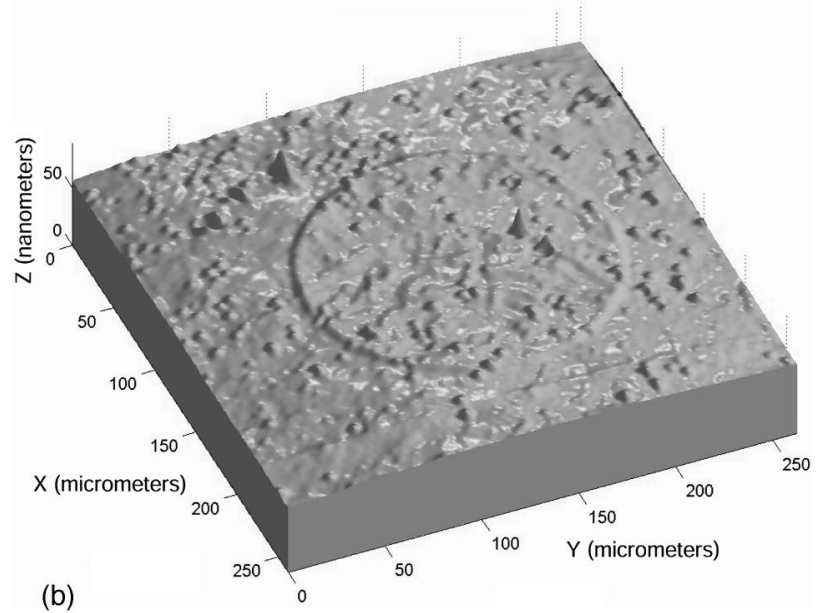

FIG. 3. Image from a "good quality" DNA microarray. (a) Hybridization of the neurochip of a fluorescent probe containing a mixture of Cy3 labeled PCR fragments corresponding to all of the DNA fragments spotted; spots are well rounded and homogeneous; (b) 3D image of a spot (exposure time $1 \mathrm{~s}$, lateral resolution $=1.6 \mu \mathrm{m})$ : the spot is clearly observed.

equivalent to $60-80 \mathrm{pm}$, which is much lower than the typical spot height.

The two presented slides contain rat brain mRNA (10 $\mathrm{nl} / \mathrm{spot}$ of a $100 \mathrm{ng} / \mu \mathrm{l}$ solution). Figures 3(b) and 4(b) show two spots from two DNA microarray experiments [Figs. 3(a) and $4(\mathrm{a})$, respectively] observed with $(\times 10, \mathrm{NA}=0.25) \mathrm{mi}-$ croscope objectives with an exposure time of $1 \mathrm{~s}$ [the total time is $1 \mathrm{~s}$ of acquisition/exposure time plus $\sim 1$ more second for phase unwrapping and three-dimensional representation]. The spots and the coating on the glass surface can be clearly identified. Figure 4(b) evidences a higher roughness around the spot than Fig. 3(b). This roughness $(\sim 15 \mathrm{~nm})$ is most likely due to the polylysine coating. Moreover, we have found a correlation between the comet tails such as observed in Fig. 4(a) and the high roughness such as seen in Fig. 4(b). In fact, the spotted DNA, related for some reason to flaws in the coating, exhibits some tendency to migrate outside the

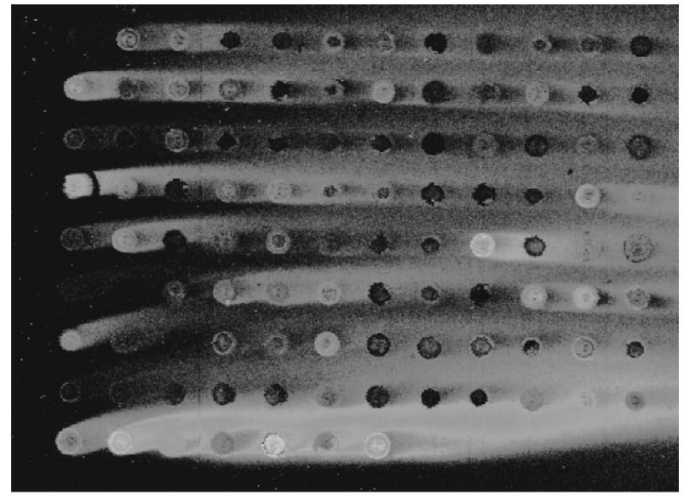

(a)

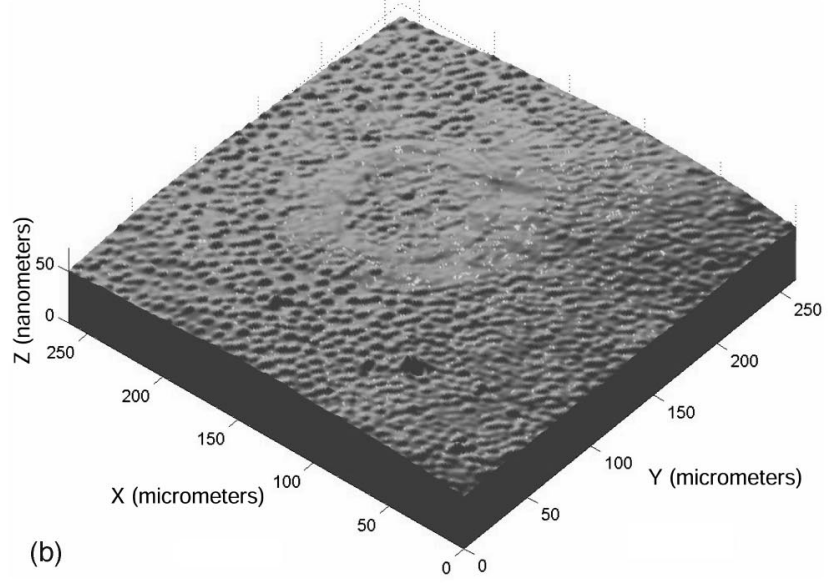

FIG. 4. Image from a "poor quality" DNA microarray. (a) Hybridization of a fluorescent cDNA obtained from rat brain mRNAs; spots are present but we observe comet tails along a particular direction; (b) 3D image of a spot (exposure time $1 \mathrm{~s}$, lateral resolution $=1.6 \mu \mathrm{m}$ ): the roughness of the sample around the spot is much higher than in the case of Fig. 3(b).

spot. Therefore, hybridization does not occur only on the spot and the fluorescent image reveals defects that make any measurement meaningless.

The authors are grateful to M. Leliboux and P. Piart for mechanical conception and realization and to L. Pottier for discussions. This work was supported by the CNRS and the DGA.

${ }^{1}$ D. Shalon, S. Smith, and P. Brown, Genome Res. 6, 639 (1996).

${ }^{2}$ M. Eisen and P. Brown, Methods Enzymol. 303, 179 (1999).

${ }^{3}$ K. Creath, Prog. Opt. 26, 349 (1988).

${ }^{4}$ J. Schwider, Prog. Opt. 28, 271 (1990).

${ }^{5}$ A. Dubois, M. Lebec, and A. C. Boccara, Opt. Lett. 24, 309 (1999).

${ }^{6}$ K. Creath, Appl. Opt. 28, 3333 (1989).

${ }^{7}$ A. Dubois, J. Selb, L. Vabre, and A. C. Boccara, Appl. Opt. 39, 2326 (2000).

${ }^{8}$ D. C. Ghilia and M. D. Pritt, Two-Dimensional Phase Unwrapping (Wiley Interscience, New York, 1998), Chap. 4. 